\title{
Distributed Approach to Cloud Oriented E-Marketplaces: a Constructive Review
}

\author{
Ige Ayokunle O. ${ }^{1}$, Akingbesote A.O. ${ }^{2}$, Ogbeide O.L. ${ }^{3}$ \\ ${ }^{123}$ Computer Science Department, Adekunle Ajasin University, \\ Akungba - Akoko, Ondo State Nigeria.
}

\begin{abstract}
:
The need to have rapid access to diverse services by various customers brought about the introduction of cloud oriented e-marketplaces. The goal of the cloud e-marketplace is to attract the highest possible number of buyers and also ensure that quality service delivery is sustained. Although, various literatures exist on cloud oriented marketplace, however most of the reports have their short-falls. This review paper provides better information on cloud oriented e-marketplaces by discussing the evolution, features, existing research, challenges and in addition, concluded that since most studies on cloud oriented e-marketplaces have proposed the use of multiple servers for performance optimization, that the management policies used in achieving effective service delivery in distributed systems be adopted in cloud e-marketplaces' server optimization. This will allow other researchers to significantly contribute to the persistent issue of balancing customer's waiting time with provider's cost. For future work, experiments to prove the effectiveness of adopting distributed approaches in cloud oriented e-marketplaces will be carried out. For this reason, the term "constructive review" is emphasized.
\end{abstract}

Keywords: marketplaces; e-market; cloud oriented; cloud marketplaces; cloud infrastructures; constructive; review

\section{Introduction}

E-marketplace is the virtual environment for buying and selling of services[1]. Various literatures have tried to give the best definition to the emarketplace, example is in [2], where it was defined as an online market environment over the internet where both sellers and buyers act as market players to exchange goods and services. The authors in [3] defined a marketplace as an area of exchange in which many buyers and vendors meet in order to conduct business transactions, and stated that a key difference exist between e-marketplaces in traditional e-commerce situations in which many buyers negotiate with one vendor, and eprocurement situations in which one buyer negotiates with many vendors. The goal of the emarketplace is to attract the biggest possible number of buyers and suppliers, which will become members of that e-marketplace [4].

The author in [5] concluded that with the development of internet, buyers and sellers use the internet as a quick and timely communication channel, and switch to conduct business online.
Conducting businesses online has numerous advantages, because it ensures that provider's goods and services reach a whole lot of potential customers and also ensures that customers have a lot of options to choose from. For a customer to choose a particular service provider, a lot of conditions are involved, but research has shown that the time it takes for a service provider to provide the required service is a very important factor. Therefore, a cloud service provider that prolongs customer's waiting time tends to lose customers regardless of the quality of the service being provided.

In order to service a customer's request without delay, cloud service infrastructures should be available and allocated effectively. The need to balance provider's cost with customer's waiting time brought about research on cloud oriented marketplaces' infrastructures.

\section{Literature}

There are three main functions of a marketplace according to [2] and they are listed as: (i) Matching of buyers and sellers (ii) Facilitating the exchange of information, goods, services, and associated (iii) 
Providing an infrastructure that enables the efficient functioning of the.

The authors in [6] categorized e-marketplaces into different types according to their ownership or governance. These types are:

1. Private Marketplace

2. Public Marketplace

3. Consortia Marketplace

4. Community Marketplace

Also, the author in [7] classified e-marketplaces into categories based on the way in which they are operated. The types are:

1. Independent E-marketplace

2. Buyer oriented E-marketplaces

3. Supplier-oriented E-Marketplace

4. Vertical and Horizontal E-marketplaces

The authors in [2], developed a Reference model for e-marketplaces that defines three phases: the information phase, agreement phase and settlement phase; which is a relative improvement on the reference model developed for e-marketplaces in [8]. The benefits of e-marketplace was explicitly differentiated between Buyers and consumers in [7]. These benefits include:

1) Benefits for the buyers:

- Updated information on price and availability makes it easier to secure the best deal.

- E-marketplaces offer a convenient way to compare prices and products from a single source rather than spending time contacting each individual supplier.

- Established e-marketplaces provide a level of trust for the buyer as they are dealing exclusively with suppliers who are members.

\section{2) Benefits for the seller}

- Regular requests for quotations from both new and current customers are possible.

- It provides an additional sales channel to market and sell products.

- The use of international e-marketplaces can provide opportunities for overseas sales that one would not otherwise be aware of.

The authors in [9] mentioned that the major reasons behind businesses using E-Marketplaces are for purchasers to lower purchasing price or run more efficient purchasing operations, and for suppliers to establish new markets or reduce sales risks.

\subsection{Evolution of Cloud E-Marketplaces}

Akingbesote in [10] listed the evolution of emarketplaces from the Traditional Marketplaces to Internet marketplaces to Web-Service Marketplace to Grid Marketplaces and Cloud Marketplaces.
A traditional marketplace is a location where buyers and sellers come together to perform transactions. The buyer and seller meet in person to talk about the product, price and in some cases delivery arrangements[11]. Researches in [12] and [13] have tried to highlight the importance and diversity of traditional marketplace. The traditional e-marketplace is a web portal where buyers and suppliers come together to explore new business opportunities[4]. Traditional marketplace can be said to be the foundation on which all other marketplaces were built. The authors in [14] listed some benefits of traditional marketplaces and explained that one can easily reach the local target audience, and also stated that marketing is easier in traditional marketplaces.

The author in [4] stated one major challenge facing traditional marketplaces which is being effective only when dealing with simple exchanges. The limitations of the traditional market brought about the concept of internet marketplaces.

\section{b) Internet E-Marketplaces}

The authors in [2] defined an electronic marketplace or e-marketplace as an online market environment over the Internet where both sellers and buyers act as market players to exchange goods and services. The author in [15] listed some benefits of the internet marketplaces as; richness, cost effectiveness and extra value provisioning as. Internet marketplaces reshaped the way in which business transactions are carried out. Research in [16] highlighted the emergence of Service Oriented Architecture (SOA) which internet e-marketplaces couldn't cope with as the reason for the introduction of Web Service marketplaces.

\section{c) Web Service Marketplaces}

The authors in [17] listed three benefits of web service marketplace as; (i) a third-party service, once implemented, can be reused across all applications. (ii) cloud providers vet every service listed on their marketplace, which in turn allows customers to use the services offered in a marketplace without having to vet them on their own, and (iii) that the marketplace will standardize the ability to add to the cloud's functionalities.

\section{d) Grid E-Marketplaces}

The advent of grid e-market is the inability of the web service e-marketplaces to perform at its best when used for high computational power. The author in [16] explained Grid e-market as a market where computational power is purchased

\section{a) Traditional Marketplace:}




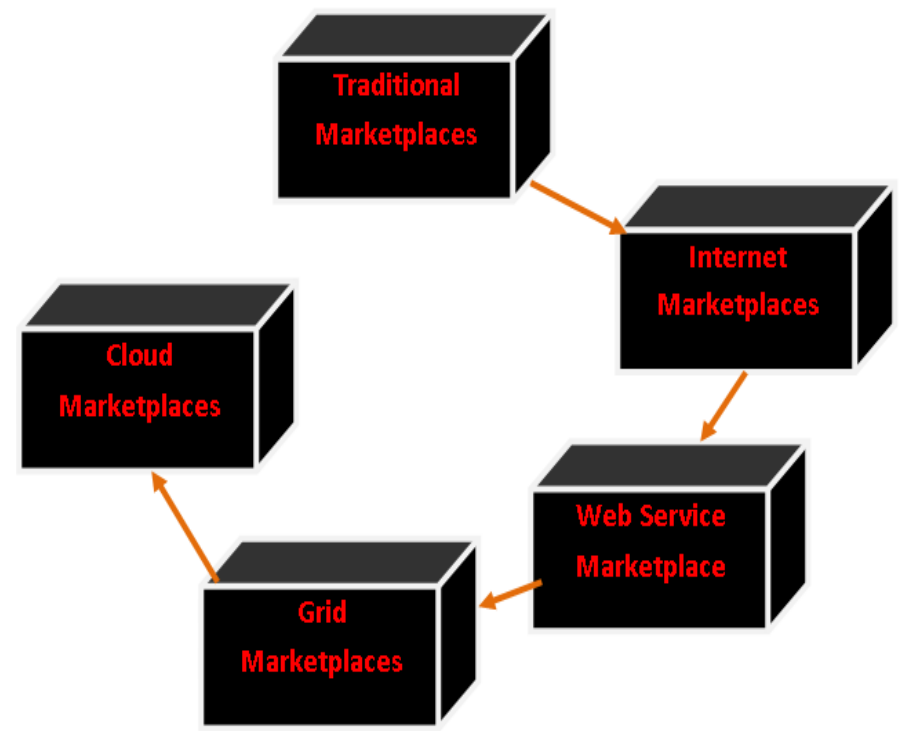

by consumers, through the use of middleware or a resource allocation broker. The basic idea of the grid marketplace is to allow customers to pull resources that are distributed across multiple locations in the same way electronic gadgets, such as televisions, fans, air conditioner pull power from source. The limitations of grid marketplace brought about cloud e-marketplaces.

\section{e) Cloud E-Marketplaces}

Research on market driven resource allocation started in the early 1980s [18]. The basic theory of cloud computing is that IT resources are made available, within an environment that enables them to be used, via a communications network, as a service [19]. There are two classifications of IT resources; it can be either raw computation resources, or certain computation resources [20]. The adoption of cloud in e-market refers to not only "the applications delivered as services over the Internet" but also "the infrastructures and systems in the datacenters"[21]. A lot of businesses are utilizing cloud services. Gartner in [22] said worldwide public cloud service was projected to grow 18percent in 2017 to total $\$ 246.8$ billion, up from \$209.2billion in 2016. Gartner also said the highest growth will come from cloud system infrastructure service which was projected to grow 36.8 percent in 2017 to reach $\$ 34.6$, and forecast the global public cloud service market will grow to reach almost $\$ 247$ billion soon and grow to $\$ 383$ billion by 2020 .

GLOBAL MARKET

OF PUBLIC CLOUD SERVICES
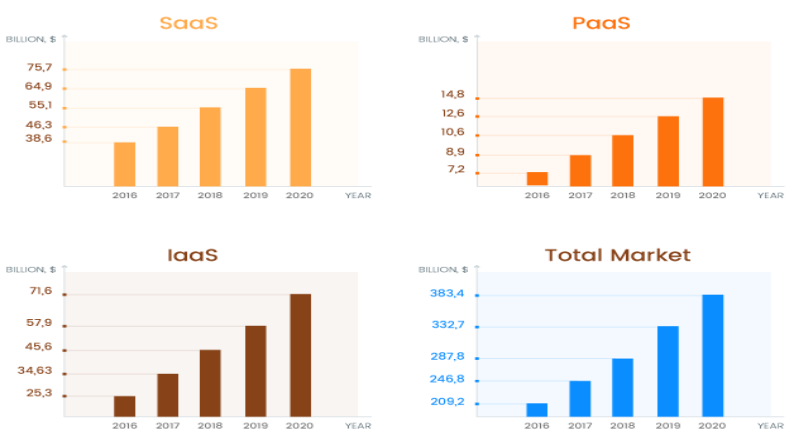

Figure 1: Forecasting the growth of cloud models. (Gartner 2017)

The benefits of the cloud market service as described in [23] are scalability, cost effectiveness, immediate availability and performance.

Cloud services are generally associated with three main models: Software as a Service (SaaS), Platform as a Service (PaaS) and Infrastructure as a Service (IaaS) [24].

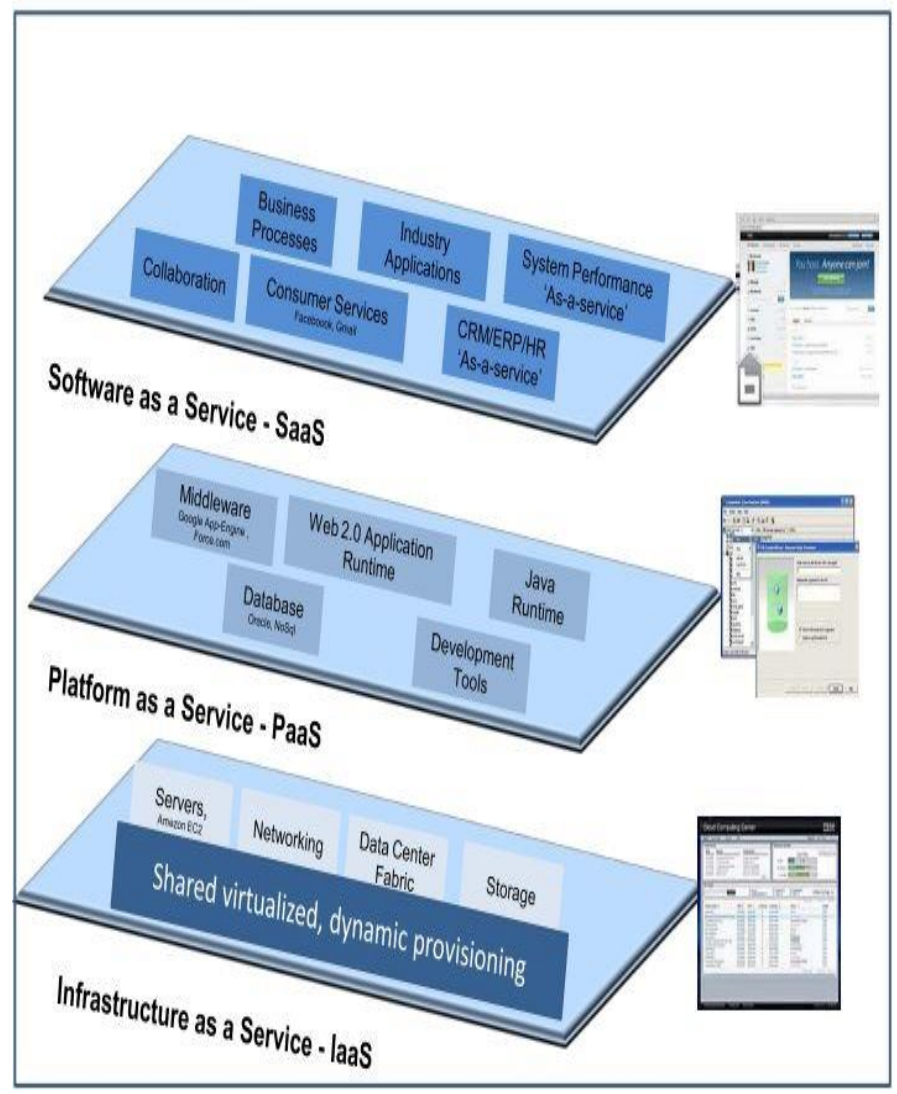

Figure 2: Service Models in Cloud

The reasons for adopting the various cloud models and their advantages were classified and explained in [23]. 


\begin{tabular}{|c|l|l|}
\hline $\begin{array}{c}\text { REASO } \\
\text { NS TO } \\
\text { USE }\end{array}$ & \multicolumn{1}{|c|}{$\begin{array}{c}\text { REASONS TO USE } \\
\text { PaaS }\end{array}$} & $\begin{array}{l}\text { REASONS } \\
\text { TO USE } \\
\text { IaaS }\end{array}$ \\
\hline $\begin{array}{l}\text { Personal } \\
\text { purposes }\end{array}$ & $\begin{array}{l}\text { Reduced development } \\
\text { ime }\end{array}$ & $\begin{array}{l}\text { Website or } \\
\text { application } \\
\text { hosting }\end{array}$ \\
\hline Business & $\begin{array}{l}\text { Support for different } \\
\text { programming } \\
\text { languages }\end{array}$ & $\begin{array}{l}\text { Virtual data } \\
\text { centres }\end{array}$ \\
\hline & $\begin{array}{l}\text { Easy collaboration for } \\
\text { remote and distributed } \\
\text { teams }\end{array}$ & $\begin{array}{l}\text { Data } \\
\text { analysis }\end{array}$ \\
\hline $\begin{array}{l}\text { High development } \\
\text { capabilities without } \\
\text { additional staff }\end{array}$ & $\begin{array}{l}\text { No expenses } \\
\text { on } \\
\text { hardware } \\
\text { infrastructu } \\
\text { re }\end{array}$ \\
\hline
\end{tabular}

Ezenwoke in [25] considered the cloud emarketplace as an ecosystem that host heterogeneous cloud services from different cloud providers and supports collaboration. The author developed a cloud service selection framework that has a feature that aids numerous customers' requirements.

Cloud service providers are faced with various users with various demands. The cloud vendor desires to meet the various demands to maximize profits corresponding to which diversified pricing policies are considered necessary. Meanwhile, a variety of request durations creates a dynamic computing resource allocation problem [26].

\subsection{Existing Approaches To Resource Allocation Problem}

The authors in [27] highlighted compute resources, networking resources, storage resources and power resources as the main types of resources that a cloud service provider can provide for customers. The author in [28] concluded that an efficient resource allocation method should meet some criteria such as cost reduction, power reduction, energy reduction, Quality of Service (QoS) enhancement, and utilization of resources.

In [29], the author focused on scheduling customer requests for SaaS providers with the explicit aim of cost minimization with dynamic demands handling. The author considered the customers' requests for an enterprise software services from a SaaS provider by agreeing to the pre-defined Service level Agreement (SLA) clauses and submitting their Quality of Service (QoS) parameters. The author in [29] allowed customers to dynamically change their requirements and usage of the hosted software services. The SaaS provider can use their own infrastructure or outsourced resources from public IaaS providers. The SaaS provider's objective is to schedule a request such that its profit is maximized while the customers' (QoS) requirements are assured.

Three cost driven algorithms were proposed also in [29] to enable service providers to maximize profit:

1. Base Algorithm: Maximizing the profit by minimizing the number of SLA violations

2. Proposed Algorithm: Maximizing the profit by minimizing the cost by reusing Virtual Machines/Servers, which have maximum available space and also,

3. Maximizing the profit by minimizing the cost by reusing Virtual Machines/Servers, which have minimum available space.

The research focused on profit maximization on Service provider's side by minimizing violations of pre-defined Service Level Agreements and re-using servers, the author measured the effectiveness of the algorithms based on some parameters: Arrival rate variation, Impact of QoS parameters, and others. However, the author only focused on Quality of Service for customers and did not consider optimizing the performance of the Servers to reduce customer's waiting time.

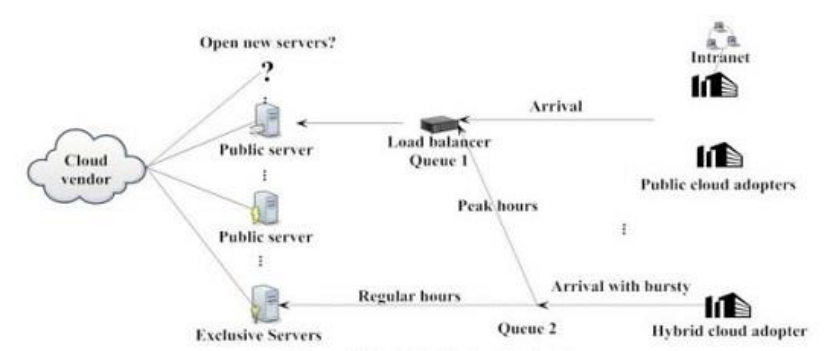

Figure 3: Model developed in Linna Du 2012

The author in [26], focused on allocating resources in a way that is sensible and cost effective by considering two cloud deployment models, the author called one deployment model the hybrid cloud which faces contract adopters who choose to rent exclusive Virtual Machine servers to handle the IT workload of regular hours but also buy public computing resources to handle peak hours' IT workload, and called another deployment model a public cloud which faces walk-in adopters who choose to only buy pooled resources when they need but willing to pay high prices. The author assumed that all physical machines are identical and parallel. Similarly, the author also assumed that the duration of each request for individual arrivals are independent and identically distributed non-negative random variables and are independent of the arrival 
process. The probability distributions of the pattern of arrivals are assumed by the author to follow poisson distributions with different arrival rates. The service distributions are assumed to follow exponential distributions. The public cloud follows "first come first served" in most of the case. However, when the hybrid adopters have heavy traffic that could not be handled by the exclusive Virtual Servers, those requests wait in the private Virtual Machine with a probability and also departs with a probability and jump into the line of public cloud with a priority. A delay cost per unit time per request is generated due to this congestion. The result in this research showed that the developed model could help cloud providers decide which deployment model to be chosen and also know if the numbers of servers on the server far should be increased.

The author in [30] modeled a cloud server farm as a queuing system which indicates that the inter-arrival time of requests is exponentially distributed, while task service times are independent and identically distributed random variables that follow a general distribution with mean value of $\mu$. The author considered the developed model to contain $\mathrm{m}$ number of servers which renders service in First come First serve basis. The author modeled the arrival process as a markovian process by exploiting [31], but stated that his work can be classified as "Semi-Markovian". The research concluded that due to the nature of the cloud environment, the general service time for request is assumed as well as large number of servers, which makes the developed model in [30] flexible in terms of scalability and diversity of service time. Numerical analysis and simulation carried out to validate the model showed that the approximate method used provides results with high degree of accuracy for the mean number of tasks in the system, and also indicates that a cloud centre that accommodates heterogeneous services may impose longer waiting time for its clients compared to its homogeneous equivalent with the same traffic intensity. However, it does not discuss successful management of server farms.

In [32], towards minimizing consumer's waiting time, the authors developed a prescriptive model that changes the numbers of servers dynamically based on consumer's waiting time. The authors employed the N-Policy as seen in [33] which enables the servers to be turned on when the system is busy and turned off when it is idle. [32] developed a model that consist of a fixed number of servers (M1, M2, M3) and a limited set of backup servers called reservoir servers. The model works by transferring consumers to reserved centres when the waiting time of the consumer reaches a point denoted by "N". The authors used queuing theory as the proof of concept. The result obtained when the model was compared to other models with fixed number of servers revealed a better performance in terms of server utilization and optimal server provisioning and also, the cost benefit accrued using this model is greater than the cost, therefore concluding that the developed model is profitable.

\section{Cloud E-Market Infrastructure}

The infrastructure of a cloud e-marketplace consist mainly of the cloud service provider, the customers requesting a service, the servers used for service and all other systems being used in cloud market service delivery. Most works that have tried to increase performance in cloud e-marketplace for example [28][34][35][36][16], have all focused on increasing the performance of the servers used in service delivery.

The use of multiple servers for cloud marketplaces' service delivery was proposed in [32][29][37][38][30]. Even though this has been significantly effective in reducing both waiting time and service provider's cost, there is still room for improvement. Since the rationale behind deployment of multiple servers in cloud emarketplaces is to achieve optimized performance, which is the same as the main objective of distributed systems' research, see for example [39] [40] [41], we therefore suggest improving the performance of cloud oriented e-marketplaces by considering multiple servers as a group of distributed systems. A lot of techniques that have been used in optimizing the reliability of distributed systems can be adopted in optimizing the performance of the cloud e-marketplaces' infrastructure.

\subsection{Conclusion}

This paper has been able to investigate and discuss the evolution of the cloud oriented marketplaces, the limitations, and also the future directions of the cloud e-marketplace. Furthermore, since most works reviewed in this paper have employed the use of multiple servers in increasing the performance of their systems, we therefore suggest that for future research on cloud marketplaces with respect to servers optimization, that the management policies used in achieving effective service delivery in distributed systems be adopted in cloud emarketplaces' server optimization. This will allow other researchers to significantly contribute to the persistent issue of balancing customer's waiting time with provider's cost. 


\subsection{Future Work}

The assumption of this constructive review is that cloud service delivery will be more effective with respect to reduced waiting time and increased profit, if existing approaches to distributed systems are adopted in managing the servers used by the cloud service providers for cloud service delivery. This is yet to be proved. So for future work, a cloud emarket model that utilizes an existing approach in distributed systems will be developed and tested against existing cloud e-marketplace model.

\subsection{References}

[1] A. O. Akingbesote, M. O. Adigun, S. S. Xulu, and E. Jembere, "Performance evaluation of cloud e-marketplaces using non preemptive queuing model," 2014 World Congr. Sustain. Technol. WCST 2014, pp. 66-71, 2015.

[2] C. Giovanoli, P. Pulikal, and S. G. Grivas, "E-Marketplace for Cloud Services," Cloud Comput. 2014 Fifth Int. Conf. Cloud Comput. Grids, Virtualization E-Marketplace, no. c, pp. 76-83, 2014.

[3] A. Ailijiang, A. Charapko, and M. Demirbas, "Consensus in the cloud: Paxos systems demystified," 2016 25th Int. Conf. Comput. Commun. Networks, ICCCN 2016, 2016.

[4] P. Taylor, "Building an e-marketplace on a peer-to-peer infrastructure," Int. J. Comput. Integr. Manuf., no. January 2015, pp. 37-41, 2015.

[5] Q. Honghong, "A model for value-added emarket provisioning: case study from," Proc. 2008 2nd Int. Conf. Futur. Gener. Commun. Networking, FGCN 2008, vol. 1, pp. 47-52, 2008.

[6] S. Sundareswaran, A. Squicciarini, and D. Lin, "A brokerage-based approach for cloud service selection," in Proceedings - 2012 IEEE 5th International Conference on Cloud Computing, CLOUD 2012, 2012, pp. 558565.

[7] NIBusiness, "E-marketplaces, online auctions and exchanges," 2016. [Online]. Available: https://www.nibusinessinfo.co.uk/content/typ es-e-marketplace. [Accessed: 18-Apr-2018].

[8] M. A. Lindemann and B. F. Schmid, "Framework for Specifying, Building, and Operating Electronic Markets," Int. J. Electron. Commer., vol. 3, no. 2, pp. 7-21, 1998.
[9] K. Rowley, Chris Hee-Dong, Yang Sora, "Electronic-marketplaces and their evolving benefits over time," Part 1 Mark. Types Res. Quest., no. July, 2009.

[10] Akingbesote A.O., "Survey on the Performance Evaluation of Electronic Marketplaces," Comput. Inf. Syst. Dev. informatics Allied Res. J., vol. 7, no. 3, pp. 15-28, 2016.

[11] Louise Balle, "Difference Between a Marketplace and an eMarketspace | Chron.com," 2016. [Online]. Available: http://smallbusiness.chron.com/differencebetween-marketplace-emarketspace25645.html. [Accessed: 19-Apr-2018].

[12] R. Curran et al., "The traditional marketplace: serious leisure and recommending authentic travel," Serv. Ind. J., vol. 0, no. 0, pp. 1-17, 2018.

[13] S. Gonzalez and P. Waley, "Traditional retail markets: The new gentrification frontier?," Antipode, vol. 45, no. 4, pp. 965-983, 2013.

[14] J. Cave, "Digital Marketing Vs. Traditional Marketing: Which One is Better," Digital Doughnut, 2016. [Online]. Available: https://www.digitaldoughnut.com/articles/201 6/july/digital-marketing-vs-traditionalmarketing.

[15] Heck, Kambil, and Van, "How Firms Can Design and Profit from Online Auctions and Exchanges," Harvard Bus. Press., 2002.

[16] Akingbesote A.O, "Modelling the performance of web services in cloud emarketplaces based on consumer waiting time and provider cost," 2014.

[17] W. Zhe and H. V Madhyastha, "Rethinking Cloud Service Marketplaces," in Proceedings of the 15th ACM Workshop on Hot Topics in Networks - HotNets '16, 2016, pp. 134-140.

[18] Y. Yemini, "Selfish Optimization in Computer networks," Comput. Sci. Dep. Columbia Univ., no. August, pp. 1-5, 1981.

[19] P. Balco, J. Law, and M. Drahošová, "Cloud market analysis from customer perspective," in Procedia Computer Science, 2017, vol. 109, pp. 1022-1027.

[20] M. Stoshikj, N. Kryvinska, and C. Strauss, "Efficient managing of complex programs with project management services," Glob. J. Flex. Syst. Manag., vol. 15, no. 1, pp. 25-38, 
2014.

[21] M. Armbrust, A. Fox, R. Griffith, A. Joseph, and RH, "Above the clouds: A Berkeley view of cloud computing," Univ. California, Berkeley, Tech. Rep. UCB , pp. 07-013, 2009.

[22] Gartner, "Gartner says worldwide public cloud services Market to grow 18percent in 2017," 2017. [Online]. Available: www.gartner.com/newsroom/id/3616417.

[23] Gleb, "Choosing the right cloud service: IaaS, PaaS, or SaaS," http://rubygarage.org/blog/iaas-vs-paas-vssaas, 2017. [Online]. Available: https://rubygarage.org/blog/iaas-vs-paas-vssaas.

[24] P. Mell and T. Grance, "The NIST Definition of Cloud Computing Recommendations of the National Institute of Standards and Technology," Nist Spec. Publ., vol. 145, p. 7, 2011.

[25] A. Ezenwoke, O. Daramola, and M. Adigun, "Towards a Fuzzy-oriented Framework for Service Selection in Cloud e- Towards a Fuzzy-oriented Framework for Service Selection in Cloud," no. January, 2017.

[26] L. Du, "Pricing and resource allocation in a cloud computing market," Proc. - 12th IEEE/ACM Int. Symp. Clust. Cloud Grid Comput. CCGrid 2012, pp. 817-822, 2012.

[27] B. Jennings and R. Stadler, "Resource Management in Clouds : Survey and Research Challenges," 2014.

[28] S. M. Parikh, "A survey on cloud computing resource allocation techniques.," Pap. Present. 2013 Nirma Univ. Int. Conf. Eng., 2013.

[29] L. Wu, S. K. Garg, and R. Buyya, "SLABased Resource Allocation for Software as a Service Provider (SaaS) in Cloud Computing Environments," in 2011 11th IEEE/ACM International Symposium on Cluster, Cloud and Grid Computing, 2011, pp. 195-204.

[30] H. Khazaei, J. Misic, and V. B. Misic, "Performance analysis of cloud computing centers using $\mathrm{M} / \mathrm{G} / \mathrm{m} / \mathrm{m}+\mathrm{r}$ queuing systems," IEEE Trans. Parallel Distrib. Syst., vol. 23, no. 5, pp. 936-943, 2012.

[31] G. G. and D. Stirzaker, "Probability and Random Processes," in third ed. Oxford Univ. Press, 2010.
[32] A. . Akingbesote and M. O. Adigun, "Perfomance modeling of Cloud Emarketplace using Dynamic Control Model," December 2014 Sci. Res. Ann., vol. Vol. 6, no. No 1, pp. 69-79, 2014.

[33] M. Yadin and P. Naor, "Queueing Systems with a Removable Service Station Queueing Systems with a Removable Service Stationt," Source OR, vol. 14, no. 4, pp. 393-405, 1963.

[34] N. Moganarangan, R. G. Babukarthik, S. Bhuvaneswari, M. S. S. Basha, and P. Dhavachelvan, "A novel algorithm for reducing energy-consumption in cloud computing environment: Web service computing approach," J. King Saud Univ. Comput. Inf. Sci., vol. 28, no. 1, pp. 55-67, 2016.

[35] F. Sheikholeslami, "Auction-based resource allocation mechanisms in the cloud environments : A review of the literature and reflection on future challenges," no. January, pp. 1-15, 2018.

[36] Q. Duan, “Author' s Accepted Manuscript Cloud Service Performance Evaluation: Status, Challenges, and Opportunities - A Survey from the System Modeling Perspective," Digit. Commun. Networks, 2016.

[37] B. Pittl and E. Schikuta, "A NegotiationBased Resource Allocation Model in," 2015.

[38] Y. Choi and Y. Lim, "Optimization Approach for Resource Allocation on Cloud Computing for IoT," Int. J. Distrib. Sens. Networks, vol. 2016, 2016.

[39] H. Wang and Y. Wang, "Maximizing reliability and performance with reliability driven task scheduling in heterogeneous distributed computing systems," J. Ambient Intell. Humaniz. Comput., vol. 0, no. 0, p. 0, 2018.

[40] I. Hosseini, S. V. Naghavi, and A. Akbar, "Distributed Model Predictive Control Strategy for a Class of Interconnected Discrete-Time Systems with Communication Delay," Iran. J. Sci. Technol. Trans. Electr. Eng., vol. 1, 2018.

[41] A. Abbas and J. Syed, "Model-Based Design and Adaptive Scheduling of Distributed RealTime Systems," 2018. 